\title{
Understanding of the principle of Autonomy (Part 1)
}

SADJ July 2018, Vol 73 no 6 p418 - p420

PD Motloba

The aim of this paper is to provide a broad overview of the notion and basic theory of autonomy, with specific focus on its definition and distinctive concepts, its importance and value. Case examples are used to illustrate the concepts.

\section{DEFINITION(S)}

The evolution of the concept of autonomy can be traced back to ancient Greece, a period in which cities defended the ideas of sovereignty and freedom from interference by foreign powers. Hence, autonomy implied self-rule, selfdetermination and self-ownership. A direct translation of the word autonomy is self rule, from autonomia (n.), and autonomos, (adj.), autos - self and nomos - rule. The modern day concept addresses personal or individual autonomy insofar as the agent may elect to act, or not to act, according to specified prescribed standards, norms or rules (which may have neutral value or be value laden). It is generally accepted that autonomy is that condition when an agent may determine the conception, the articulation and the execution of concepts, ideas and actions for him or her -self.

\section{DISTINCTIVE CONCEPTS OF AUTONOMY}

Despite agreement on the basic precepts, several theories of autonomy have emerged over time, under the influence of law, politics, philosophy and religious precepts. Consequently, 'autonomy' has different connotations, unevenly understood and applied in a variety of ways. At root level, autonomy means having the capacity to self-govern, which is the ability to act independently, responsibly and with conviction. This concept of autonomy relies on the agency of a moral being to exercise his/her own decisions about his/her being. Legally, the agency of an individual or capacity for self-rule is concerned with mental competence and cognitive capability to make decision at a particular time, hence legal age is used as a proxy for mental and cognitive capacity., ${ }^{1,2}$ This legal threshold fails to acknowledge autonomy as a continuum, beginning with an agent without capacity until full capacity is reached, which can be achieved at different times and to different degrees. Furthermore, this mental capacity can

Prof. Pagollang D Motloba: BDS (Medunsa), MPH (Epidemiology) (Tulane), M Dent (Comm Dent) (Medunsa), MBL (Unisa). Chief Specialist, Head, Department of Community Dentistry, School of Oral Health Sciences - Sefako Makgatho Health Science University (SMU), South Africa.

Tel: +27 12 521- 4848/5767. Email: pagollang.motloba@smu.ac.za attenuate or be lost even after reaching the threshold. For example, due to deterioration of the brain, an adult could lose moral agency or the ability to exercise reasonable decision-making.

Influenced by Western thought, autonomy refers to the entitlements and rights, the liberties and freedom to make decisions for oneself without interference. However, having the freedom to self-govern does not necessarily mean that the agent will simultaneously have the capacity and the opportunity to exercise the right of self-rule. ${ }^{3}$ For example, family position and status can compromise or improve one's ability to self-determine. Philosophically, the concept of autonomy is idealized beyond capacities and sets of rights. According to this framework, the goal is to achieve a state of fully developed autonomy characterized by settled dispositions and the skills to self-govern. Individuals with these levels of development are less likely to be affected by chance, contingency or weakness of will in exercising self-rule. ${ }^{4}$

To exemplify these concepts, imagine Mrs. Sono (49 years), a loyal patient of over twenty years at Dr Matsho's private rooms. During her recent dental visit, she courteously suggested to the locum dentist that "Dr, whatever treatment you plan to do, you don't have to ask me for permission. Dr Matsho treated me well all the time and I trust that you will do the same since you work for him". Mrs Sono can be said to have relinquished her autonomy, by giving up her capacity to determine the course of her dental treatment. This does not, however, mean that she lacks the capacity or the legal right to do so. On the contrary she decisively exercised her autonomy to abstain from making any choices related to her care.

Now envision John, a 25-year-old prisoner, who urgently needs root canal treatment, which is unfortunately unavailable in the prison oral health system. The prison authorities organized with nearby facilities in order to provide the preferred treatment, failing which dental extractions would be performed in the prison facility to relieve his symptoms. In John's case autonomy is constrained by the structural and operational limitations of the prison health facility. While he has the capacity to make an autonomous choice in deciding the preferred treatment, the opportunities and conditions to realize his choice or to self-govern are structurally limited. 
Mary, a responsible 15 year old, trusted by her parents and teachers for being thoughtful and rational in decision making, presented at your dental office requesting tooth whitening even though it was contraindicated in your expert opinion. She insisted it was for necessary for her to look prettier, oblivious to associated side effects. Mary's case elucidates the concept of developing autonomy. Because of her young age and limited exposure and life experience, she has not developed adequate levels of autonomy. She does not lack the capacity to self-determine; her capacity is merely limited and constrained by external factors.

The contrary case is about Paul, a 25 years old chronic user and addict to marijuana, alcohol and drugs for over 10 years. He recently completed a three month rehabilitation program and has not used drugs in over seven months. On his visit to your dental practice, you observe the worst oral hygiene ever. Upon questioning Paul, he said, "Doc, all these teeth don't matter to me, I want to take them all out and buy myself a brand new set of false teeth instead." Paul represents an agent with under-developed autonomy. Despite having the legal right to make decisions; his ability to do so is limited. Unlike Mary, Paul's incompetence is not attributable to age and experience but to a state of dysfunction related to substance abuse. Whatever decisions Paul make, it remains questionable whether they would have been considered and thought-through. or are impulsive and imprudent. Overall Paul lacks the virtues that resemble the ideal autonomous agency.

Finally, Simon collapses in your rooms due to hypoglycemia during routine dental treatment, forcing you to terminate the dental treatment until further notice. Simon is wholly unautomonous, he does not possess the capacity and lacks the legal right and agency for decision making.

These vignettes provide distinctive interpretations of the nature of autonomy, its scope and how it applies under different circumstances, time and context. From a moral point of view, autonomy confers status, which implies that a person is owed respect, dignity and obligations. ${ }^{1,5}$ On legal grounds, autonomy separates personal concerns from the intrusion of the State, in so doing it preserves the sphere of personal sovereignty. ${ }^{2}$ At a personal level, autonomy is indicative of a self-creation process through which a person discovers who they are, what they hope for, and want to achieve in their lives, independent of impositions by external interferences. ${ }^{4}$

Our conclusion follows established consensus that autonomy is a morally valuable principle, primarily for its own sake. Kant espouses this assertion in his suggestion that, if we value autonomy we would then "act in such a way so as to treat ourselves and others as end and never simply as a means to an end'. Second, autonomy confers instrumental value, as a "means" towards achieving some "end" with intrinsic value., ", Imagine a patient who places implants in his/her lip to achieve a certain aesthetic appeal, and in the process experiences pain and sepsis and several days of hospitalization. According to the intrinsic view, despite the unfavourability of the choices made, autonomy has to be respected. ${ }^{7}$ In this instance autonomy did not result in any value add, but loss. It could therefore be argued from a position of instrumental value that social recognition, aesthetics and looks were intended ends of the process. Therefore this choice had potential benefits, and should be regarded as autonomous.

\section{CONDITIONALITY OF AUTONOMY}

The conditions governing autonomy constitute the most contested area in moral and ethical literature. Two conditions are considered essential for autonomy, firstly, liberty or freedom from undue external influences which may enable or interfere with or hinder free decisionmaking process. Secondly, to be an agency capable of intentional acts, or the competence to comprehend, retain and interpret information, which is finally articulated as a decision reached. However, areas of disagreements remain around what these conditions mean, and whether they are sufficient or necessary.

The scope of this paper is about autonomous choice, rather than focusing on the general capacities of selfdetermination and governance. Such debates are less helpful in framing a basic theory and understanding of the principle of autonomy. Imagine for example an autonomous person who fails to act accordingly at some point due to temporary cognitive impairment, like depression. Or, take a patient who signs the consent form for a major surgical procedure without reading the document. These two cases highlight the need to construct a theoretical framework to use in evaluating the level of autonomy exercised by autonomous agents.

The Beauchamp and Childress theory of autonomy is premised on the thesis that choices of a competent person are autonomous if they are intentional, and are demonstrative of comprehension and are free from internal or external influences. ${ }^{1}$ Accordingly their analysis of autonomy focuses three non-ideal conditions:

i) Intentionality as opposed to incidentality, meaning that a plan has been developed, comprising of series of events with a set outcome in mind. ${ }^{3}$ Intentionality does not imply executing plans, often times intentions are wishes.

ii) Comprehension, an actwould bejudged as autonomous if the situation is adequately understood. ${ }^{8}$ Poor communication can severely hinder understanding; other factors that could impede understanding include immaturity, illness and irrationality due to substance abuse etc. Comprehension will vary in degrees and over the passage of time. A person might fully understand at some point in time but may be totally non-comprehending at some other time depending on the context.

iii) Voluntariness and non-control means that the actor is free from undue influence, especially coercion and manipulation. ${ }^{1,9}$

When evaluating autonomous acts according to this theory of the three conditions, one ought to establish if the act was intentional or not (there are no varying degrees of intentionality). As for comprehension and voluntariness and non-control, the levels will vary to some degree. An individual might be under total control ranging to absolutely none; might fully understand down to lacking the faintest idea. While outright objectivity might be difficult to achieve, a line must be drawn to indicate sufficient or inadequate understanding. Similarly, a measure must be developed indicative of control and non-control. These 
thresholds are particularly useful in determining the degree of autonomous choice, and how substantial or not is the decision making in a particular context.

\section{APPLYING THE THEORY IN PRACTICE}

Mr. Piet, a 59-year-old man with multiple chronic dental problems consulted your practice, indicating that he had not slept the night before due to severe dental pain. At the time of the dental visit, the pain has subsided, and the patient was requesting anterior gold inlays on asymptomatic but carious 21, 22, 11 and 12. After explaining your findings and the seriousness and urgency of commencing dental treatment, the patient insisted on his gold inlays and threatened to go somewhere else if not assisted immediately. Can we conclude that the patient's request was autonomous? Based on the three-condition theory, a decision is autonomous if it is intentional, demonstrates an understanding of the issues at stake and is voluntary. Mr. Piet has certainly given his decision some thought, he saved huge amount of resources for this treatment, it is hence very unlikely that the decision to place gold inlays was incidental. Therefore, we could conclude that there was substantial intention on the part of the patient. Mr. Piet could be deemed competent, in that he understood his oral health status and the need to urgently have dental treatment. Despite having discussed the pros and cons of his condition, Piet refused appropriate care, and threatened to go elsewhere for gold inlays. It is plausible that Mr. Piet could have experienced some level of coercion from the dentist. It is also possible that Mr. Piet understood that request was, at that point in time, difficult to meet, hence his threat to seek care elsewhere. The refusal by the dentist to provide gold inlays cannot be interpreted as undue influence, but good and ethical clinical practice. If the patient's oral hygiene was optimal, perhaps a different argument could be made as to why inlays were refused. It is therefore appropriate to conclude that to a substantial degree, Mr. Piet's decision was autonomous. Autonomous decision by patients does not mean the clinician should accept and undertake clinical procedure. It simply implies that the patient is cognisant and is able to determine for himself how they should be treated. It is imperative for clinicians to respect the patients position or state.

\section{IMPLICATIONS FOR PRACTITIONERS}

Some authors regard autonomy as a prima facie and paramount principle in ethical debate.,10 For this reason, it is critical that the patient's autonomous status or competence be objectively established before any clinical intervention is made. Often time clinicians are too concerned about the benefits and harms associated with an intervention and disregard the centrality of autonomy in joint decision-making. ${ }^{\text {? }}$ The cases presented above highlight the need for practitioners to firstly consider the impact of individual principles in the case under review. Secondly, practitioners should identify any logical incompatibility of ethical principles and the clinical choices associated with each principle. Prior to making ethical decisions, it is critical that the contribution of each principle and the associated choices be extrapolated to the resolution of the ethical dilemmas., ${ }^{5,11,12}$ Clinical dilemmas are becoming more complex in recent times, it is thus imperative for practitioners to develop a framework to appraise and evaluate such situations in order to reach ethically and morally reasonable, sound clinical decisions.

\section{References}

1. Beauchamp TL, Childress JF. Principles of Biomedical Ethics, Oxford University Press, USA, 2013, 7th ed.

2. Buchanan A. Mental capacity, legal competence and consent to treatment. Journal of the Royal Society of Medicine 2004;97 (9):415-20.

3. Epstein RM, Peters E. Beyond information: exploring patients' preferences. Journal American Medical Association 2009; 302 (2), 195-7.

4. Campbell AV.The virtues (and vices) of the four principles. Journal of Medical Ethics 2003;29 (5): 292-6.

5. Gillon R. Medical ethics: four principles plus attention to scope. British Medical Journal 1994;309 (6948):184.

6. WilsonEE. Kant on autonomy and the value of persons. Kantian Review 2013;18 (2):241-62.

7. Gillon R. Ethics needs principles-four can encompass the rest-and respect for autonomy should be "first among equals"," Journal of Medical Ethics 2003;29 (5):307-12.

8. Clouser KD, Gert B. A critique of principlism. The Journal of Medicine and Philosophy 1990;15 (2), 219-36.

9. Roberts LW. Informed consent and the capacity for voluntarism. American Journal of Psychiatry 2002;159 (5):705-12.

10. Nelson RM, Beauchamp T, Miller VA, Reynolds W, Rittenbach RF, Luce MF.The concept of voluntary consent. The American Journal of Bioethics 2011;11 (8):6-16.

11. Veatch RM.Resolving conflicts among principles: ranking, balancing, and specifying. Kennedy Institute of Ethics Journal 1995;3:199-218.

12. Veatch RM. How many principles for bioethics?: Principles of Health Care Ethics 2006; John Wiley and Sons, Georgetown, pp43-50. 